\title{
Anger, Fear, and Sadness: How Emotions Could Help Us End a Pandemic of Racism
}

\author{
Robyn M. Catagnus ${ }^{1}$ (D) - Annette K. Griffith ${ }^{1}$ (D) Brandon J. Umphrey ${ }^{1}$ (D)
}

Accepted: 21 March 2021 / Published online: 3 June 2021

(C) Association for Behavior Analysis International 2021

\begin{abstract}
Racism, recently referred to as another kind of pandemic, affects the health and safety of diverse individuals within the United States and around the world. Emotions are a powerful and integral aspect of the experience of racism; however, within the field of behavior analysis, we have been hesitant to acknowledge emotion or explore how it relates to behavior and behavioral contingencies. As a result, the scope of our understanding of emotion is limited. To better understand the current experience and perception of practitioners in the field of behavior analysis, as they relate to emotion and racism, a brief survey was conducted. Findings indicated that although many may be comfortable discussing emotion and displaying emotions for themselves and others, this was not the case for everyone. Further, many were uncomfortable discussing racism. Although participants believed that emotions of racism are important and should be addressed by the field of behavior analysis, they think the field has not done enough work in this area. The results of the study lead to several recommendations, including additional antiracism research and the acknowledgment of emotional experience, as well as for how individuals can better understand, and maybe reduce, the negative emotions associated with oppression.
\end{abstract}

Keywords Racism $\cdot$ Antiracism $\cdot$ Emotions $\cdot$ Behavior analysis $\cdot$ Social justice

My heart hurts, my mind is angry, and there is fear that it will continue. But as an advocate for change, I want to hold onto positivity.

—Cha Asokan (Khaw, 2020, para. 17)

As the United States has dealt, yet again, with the killing of Black people at the hands of the police, a myriad of emotions have been put on display for the world to see. Graphic images and videos have been shared depicting excessive police use of force, the last moments of Black lives, and the protests and counterprotests that have taken place across the country. In all of these images, the emotions have been clear: sadness, fatigue, fear, anger, and determination, to name a few. Even if we did not personally know the people in the pictures or in the videos, we could see in them ourselves, our family, our friends, and our neighbors; their emotions became our

Robyn M. Catagnus

rcatagnus@thechicagoschool.edu

Applied Behavior Analysis Online Department, The Chicago School of Professional Psychology, Chicago, IL, USA emotions (Turnbull et al., 2020). We felt it when we heard the words "I can't breathe." We felt it when we heard police officers use racial slurs or words of indifference toward dying men. We felt it when George Floyd's 6-year-old daughter, sitting high upon shoulders with her hands in the air, sang out that her daddy had changed the world. These images were powerful not only because they shed light on the events that had occurred but also because of the strong emotions they evoked for so many.

The emotions associated with racism are not incidental. They are key to understanding the pressing public health emergencies we are facing. During 2020, the viral pandemic of COVID-19 highlighted and emphasized the inequities of a "racism pandemic" in the United States (Baker, 2020). And "the health consequences are dire. Racism is associated with a host of psychological consequences, including depression, anxiety and other serious, sometimes debilitating conditions, including post-traumatic stress disorder and substance use disorders" (American Psychological Association, 2020, para. 5).

Although few of us wouldargue that these emotions are not real or that they are not intrinsically tied to the multitude of events unfolding, as behavior analysts, we have not yet taken up the challenge of assessing emotions to understand why this 
may be the case. Whereas emotions and emotional behavior are widely accepted and discussed within the lay community and within many areas of psychology, this has not been the case in the field of behavior analysis (Anderson et al., 2000; Friman et al., 1998; Lewon \& Hayes, 2014). As a field, behavior analysis has been hesitant to acknowledge emotion and the role it may play in behavior, and thus our scope of understanding is limited (Anderson et al., 2000; Lewon \& Hayes, 2014). This gap in our knowledge and, in turn, our technologies can be detrimental in a variety of ways, but it becomes glaringly so in light of events that are as poignant as the current social justice movement. Although many behavior analysts have mobilized to define position statements, create a sense of community, advocate for equality and inclusivity, and identify how to create change, we may also be stifled by our relative neglect in considering the role of emotions so starkly present. And, at times, we may have been caught in quagmires of dissent or disagreement too.

Although it would be inaccurateto suggest that no work has been done in the field of behavior analysis in regard to emotions, as many behavior analysts have addressed emotions and private events in both experimental studies and from theoretical perspectives (e.g., Anderson et al., 2000; Burghardt, 2019; Dymond et al., 2018; T. V. J. Layng, 2017; Lewon \& Hayes, 2014; Toney \& Hayes, 2017; Vilardaga, 2009), it would be fair to state that we, as a field, have yet to come to a consensus on the ways that emotion and private events should be defined and studied (e.g., Baum, 2011; Catania, 2011; Fryling \& Hayes, 2015; Lewon \& Hayes, 2014; Palmer et al., 2004). L. J. Hayes and Fryling (2015) captured the problems with this lack of consensus when they stated, "When behavior means different things to different behavior scientists, different behavior scientists are no doubt investigating different things and the products of their investigations thereby do not all elaborate upon the collective works of other behavioral scientists" (p. 150). Although their discussion extended to behavior beyond emotion and private events, the conclusion remains the same. Without a clear consensus on the behavior under question, or consensus on whether or not our topic of focus even constitutes behavior, we are limited in our ability to extend our knowledge and our reach as agents of behavior change.

Given these complexities, the purpose of this article is to facilitate discussion regarding emotions and emotional behavior in behavior analysis, particularly within the context of racism and systemic oppression. First, it is important to distinguish emotions, private events that reflect the contingencies we experience, from emotional behaviors, the expression of which indicate how we feel or serve to communicate actions to be taken by others (T. V. J. Layng, 2006, 2017). Such public displays may become operants if they contact reinforcement (T. V. J. Layng, 2017). Emotions are part of behaviors in a particular contingency situation, not stimuli (Goldiamond, 1979), triggers, or causes, and they can help us to better understand our situation, revealing those that may be in need of change ( $T$. V. J. Layng et al., in press). In the coming sections, we share the results of a survey about the experiences and perceptions of behavior analysis professionals related to emotion and the emotions of racism. The results may help us to better understand how emotion is experienced and perceived by behavioral scientists and practitioners, with the hope that this information can help guide us to understand the complex contingencies of racism and to develop contextually situated, community-based interventions.

\section{Survey of Behavior-Analytic Practitioners}

To gain an understanding of the experience and perception of racism and associated emotions in the field of applied behavior analysis (ABA), we conducted a brief survey of practitioners. The survey consisted of 22 closed-item questions and 2 open-ended questions that sought to obtain information on (a) demographics, (b) experience with emotions in general, (c) experience with emotions while working in the field of $\mathrm{ABA}$, (d) experience with emotions related to race, and (e) perception of the role of ABA as it relates to racism. The survey was created using Microsoft Forms and distributed via email lists and social media posts using a snowball method that allowed recipients and viewers to share the recruitment information with any other individuals who may have been interested in participating (Biernacki \& Waldorf, 1981). One hundred fifty-two participants completed the survey. Although the method of distribution does not allow for the calculation of a response rate, and the participants represent only a small number of individuals working within the field of behavior analysis, this number is not inconsistent with other survey research conducted and published within the behavioranalytic literature (e.g., Taylor et al., 2019).

\section{Demographic Information}

Of the 152 participants who completed the survey, the majority were women $(n=117,77.0 \%)$, and they were on average 37.4 years old $(S D=10.3$, range $21-70)$. A little over half of the participants reported themselves to be White $(n=95$, $62.5 \%$ ), a little more than one third reported as people of color (POC; $n=53,34.9 \%$ ), and the remaining participants chose not to disclose their race $(n=4,2.6 \%)$. Of the POC, 14 reported as Black (26.4\%). The majority of participants reported that they lived in small $(n=34,22.4 \%)$, medium $(n=41$, $27.0 \%)$, or large cities $(n=71,46.7 \%)$, with only $3.9 \%(n=$ 6 ) reporting that they lived in a rural setting. The majority of participants also reported that their social circles were at least somewhat diverse $(n=143,94.0 \%)$. 
The majority of the participants reported themselves to be certified by the Behavior Analyst Certification Board (BACB), with 18 Registered Behavior Technicians (RBTs; 11.8\%), 3 Board Certified Assistant Behavior Analysts (BCaBAs; 2.0\%), 73 Board Certified Behavior Analysts (BCBAs; 48.0\%), and 34 Board Certified Behavior Analysts-Doctoral (BCBA-Ds; 22.4\%) participating. The remaining participants reported that they worked in the field of behavior analysis but that they were not certified. Participants had a range of experience within the field, with $30.3 \%$ reporting that they had worked in the field for longer than 10 years $(n=46), 30.3 \%$ reporting that they had been in the field for 5 to 10 years $(n=46)$, and the remainder reporting that they had worked in the field for less than 5 years $(n=59$, $38.8 \%$ ). Participants reported working in several different types of settings, from in-home settings ( $n=73,48.0 \%)$, to clinical settings $(n=67,44.1 \%)$, schools $(n=42,27.6 \%)$, institutions of higher education ( $n=33,21.7 \%)$, residential/ hospital settings $(n=3,2.0 \%)$, and corporate settings $(n=1$, $0.7 \%$ ); many participants reported working in more than one setting. It is difficult to discern how well the participants of this study represent individuals who are working in the field of behavior analysis, as very little data are available about this population. Although the information on gender, areas of practice, and certification level has been made public, more in-depth data on demographic characteristics are currently unknown (Connors, 2020). Based on the data that are available, men are represented in this study at a level that is slightly higher than their presence in the field (Nosik \& Grow, 2015), and both RBTs and BCaBAs are underrepresented (BACB, 2020).

\section{Comfort With Emotions}

Three questions were asked to gain an understanding of participants' comfort with emotions - specifically, how comfortable they were talking about emotions in general, how comfortable they were displaying their emotions around others, and how comfortable they were when others displayed strong emotional behavior. Data from these questions are presented in Table 1. Taken together, they suggest that although many participants were comfortable talking about emotions and with the display of emotions, this was not the case for all participants. Whereas over two thirds of participants were comfortable or very comfortable talking about emotions $(n=$ $105,69.1 \%)$, over $10 \%$ indicated that they were not $(n=20$, $13.2 \%)$. Two thirds also reported that they were comfortable or very comfortable when others displayed emotions around them $(n=99,65.1 \%)$, whereas about a fifth reported that this would make them uncomfortable or very uncomfortable ( $n=$ $27,17.8 \%$ ). Finally, whereas just over half of participants $(n=$ $83,54.6 \%$ ) were comfortable displaying emotions around others, over a quarter indicated that this made them feel uncomfortable or very uncomfortable $(n=40,26.3 \%)$.

\section{Emotions at Work in ABA}

Five questions were asked to gain an understanding of participants' perception of the role that emotions play in their work and within the field of ABA. Specifically, participants were asked how important it is for them to help their clients feel better emotionally, how likely they were to consider emotions in assessment and intervention development, and how their intervention development or revision might be impacted by emotional reactions from clients. They were also asked how empathetic they felt their colleagues were and how well the field of behavior analysis responds to emotion and considers emotions in the analysis of and intervention on behavior. Data from these questions are displayed in Table 2 and suggest that overall, the majority of participants believed that emotions play an important role in the work that they did within the field of ABA. The majority $(n=$ $136,89.5 \%$ ) reported that they agreed or strongly agreed that their job was to help their clients feel better emotionally and that they were likely or somewhat likely $(n=145,95.4 \%)$ to consider the emotions of caregivers, clients, or coworkers when conducting assessments and interpreting findings. A large proportion $(n=136,89.5 \%)$ reported that the emotional reactions of clients impacted their intervention development or revision at least some of the time, and many $(n=119$, $78.2 \%$ ) reported that their colleagues demonstrated empathy at work. They tended to disagree, however, with the statement that, in general, the field of behavior analysis responds to emotion and considers emotions in the analysis of and intervention on behavior, with $53.9 \%(n=82)$ disagreeing, $34.9 \%(n=53)$ agreeing, and $11.2 \%(n=17)$ indicating that they did not know.

\section{Emotions Related to Race}

Regarding emotions related to race and racism, participants were asked four questions. They were asked how comfortable they were discussing race and racism, and they were asked to rank their level of agreement with statements about the importance of understanding emotions related to racism and about the ability of White people to understand the experience of racism. They were then asked to list three emotions they expected individuals subjected to systemic racism to experience. Data for the first three questions are displayed in Table 3. These data indicate that although most participants were comfortable discussing racism, this was not the case for everyone, as over one quarter of participants $(n=39$, $25.7 \%$ ) indicated that they were uncomfortable talking about race and racism or that they felt neutral on the topic. However, the majority of participants, $96.7 \%(n=147)$, did 
Table 1 Comfort With Emotions

Survey item Level of comfort

\begin{tabular}{lllll}
\hline $\begin{array}{l}\text { Very } \\
\text { comfortable } \% \\
(n)\end{array}$ & $\begin{array}{l}\text { Comfortable } \\
\%(n)\end{array}$ & $\begin{array}{l}\text { Neutral } \\
\%(n)\end{array}$ & $\begin{array}{l}\text { Uncomfortable } \\
\%(n)\end{array}$ & $\begin{array}{l}\text { Very } \\
\text { uncomfortable \% } \\
(n)\end{array}$ \\
\hline $28.9(44)$ & $40.1(61)$ & $17.7(27)$ & $11.8(18)$ & $1.3(2)$ \\
$12.5(19)$ & $42.1(64)$ & $19.0(29)$ & $21.7(3)$ & $4.6(7)$ \\
$17.7(27)$ & $47.3(72)$ & $17.1(26)$ & $13.8(21)$ & $3.9(6)$
\end{tabular}

How comfortable are you talking about feelings, generally?

How comfortable are you displaying emotions around others?

$17.7(27)$

$47.3(72)$

$17.1(26) \quad 13.8(21)$

$3.9(6)$

strong emotional behavior?

Note. This table presents information about the survey questions that were asked to gain information about participant comfort with emotions in general.

report that understanding the emotions associated with racism is important, as they either agreed or strongly agreed with that statement. Whereas some participants reported that they did not know, no participants disagreed with this statement (see Fig. 1). In regard to the statement that White people can understand the experience of racism, the responses were fairly split. Although a slightly larger proportion of participants reported that they agreed with this statement ( $n$ $=63,41.4 \%)$, several participants disagreed $(n=49,32.2 \%)$ or indicated that they did not know $(n=40,26.3 \%)$. When these data were examined separately for POC compared to White individuals, the breakdown looks a little bit different, with more POC disagreeing with the statement $(n=19$, $35.8 \%)$ compared to Whites $(n=29,30.5 \%)$.

To examine the data that were gathered when participants listed the emotions that they thought individuals experiencing systemic racism may feel, the emotions have been organized into a word cloud (see Fig. 2). Words that were mentioned more often appear larger in the cloud, whereas words that were mentioned less often are smaller. Many emotions are depicted; however, anger, frustration, fear, and sadness stand out as those that were identified by the greatest number of participants.

\section{$A B A$ and Racism}

The final section of the survey asked participants three questions related to $\mathrm{ABA}$, race, and racism. The first question asked participants how comfortable they were talking about race with their behavior-analytic colleagues. The next two questions asked participants to rank their level of agreement with statements that the field of ABA should be involved in reducing racism and systematic oppression and that behavior analysts should be creating interventions to address emotions related to racism and systematic oppression. The data for these questions are presented in Table 4. Over two thirds of

Table 2 Emotions at Work in Applied Behavior Analysis

Survey item

\begin{tabular}{|c|c|c|c|c|}
\hline \multicolumn{5}{|c|}{ Level of agreement } \\
\hline $\begin{array}{l}\text { Strongly } \\
\text { agree \% } \\
\text { (n) }\end{array}$ & Agree $\%(n)$ & $\begin{array}{l}\text { I don't } \\
\text { know \% } \\
(n)\end{array}$ & Disagree $\%(n)$ & $\begin{array}{l}\text { Strongly } \\
\quad \text { disagree \% } \\
\quad(n)\end{array}$ \\
\hline $57.2(87)$ & $32.2(49)$ & $5.9(9)$ & $3.2(5)$ & $1.3(2)$ \\
\hline $27.6(42)$ & $50.6(77)$ & $13.1(20)$ & $7.2(11)$ & $1.3(2)$ \\
\hline $2.6(4)$ & $32.2(49)$ & $11.1(17)$ & $44.7(68)$ & $9.2(14)$ \\
\hline \multicolumn{5}{|c|}{ Level of likelihood } \\
\hline $\begin{array}{c}\text { Very likely } \\
\%(n)\end{array}$ & $\begin{array}{l}\text { Somewhat } \\
\text { likely \% } \\
(n)\end{array}$ & $\begin{array}{l}\text { I don't } \\
\text { know \% } \\
(n)\end{array}$ & $\begin{array}{l}\text { Somewhat } \\
\text { unlikely \% } \\
\text { (n) }\end{array}$ & $\begin{array}{c}\text { Very unlikely } \\
\%(n)\end{array}$ \\
\hline $71.0(108)$ & $24.3(37)$ & $2.6(4)$ & $1.3(2)$ & $0.6(1)$ \\
\hline
\end{tabular}

How likely are you to consider the emotions of caregivers, clients, or coworkers when conducting assessments and interpreting findings?

Survey item

How often do emotional reactions from clients impact your intervention development or revision?
How often

Always \%

(n)

$18.4(28)$
Most of the Sometimes
time $\%(n) \quad \%(n)$

30.2 (46)

40.7 (62)
Not often \%

(n)

8.5 (13)
Never \% (n)

$1.9(3)$

Note. This table presents information about the survey questions that were asked to gain information about participant experience and perceptions related to emotions at work within the field of applied behavior analysis. 
Table 3 Emotions Related to Race

\begin{tabular}{|c|c|c|c|c|c|}
\hline \multirow[t]{2}{*}{ Survey item } & \multicolumn{5}{|l|}{ Level of comfort } \\
\hline & $\begin{array}{l}\text { Very comfortable } \\
\quad \%(n)\end{array}$ & $\begin{array}{l}\text { Comfortable } \\
\%(n)\end{array}$ & Neutral \% (n) & $\begin{array}{l}\text { Uncomfortable } \\
\quad \%(n)\end{array}$ & $\begin{array}{l}\text { Very } \\
\text { uncomfortable } \\
\quad \%(n)\end{array}$ \\
\hline \multirow[t]{2}{*}{ How comfortable are you discussing race and racism? } & $26.9(41)$ & $47.3(72)$ & $13.8(21)$ & $11.1(17)$ & $0.6(1)$ \\
\hline & \multicolumn{5}{|l|}{ Level of agreement } \\
\hline Survey item & $\begin{array}{l}\text { Strongly agree } \% \\
\quad(n)\end{array}$ & Agree \% (n) & $\begin{array}{l}\text { I don't know } \\
\%(n)\end{array}$ & Disagree \% $(n)$ & $\begin{array}{l}\text { Strongly disagree } \\
\%(n)\end{array}$ \\
\hline $\begin{array}{l}\text { All participants: It is important to understand emotions } \\
\text { related to racism. }\end{array}$ & $69.0(105)$ & $27.6(42)$ & $3.2(5)$ & $0(0)$ & $0(0)$ \\
\hline $\begin{array}{l}\text { All participants: } \\
\text { White people can understand the emotions of racism. }\end{array}$ & $11.8(18)$ & $29.6(45)$ & $26.3(40)$ & $26.9(41)$ & $5.2(8)$ \\
\hline $\begin{array}{l}\text { POC participants }(n=53) \text { : } \\
\text { White people can understand the emotions of racism. }\end{array}$ & $11.3(6)$ & $26.4(14)$ & $26.4(14)$ & $28.3(15)$ & $7.5(4)$ \\
\hline $\begin{array}{l}\text { White participants ( } n=95) \text { : } \\
\text { White people can understand the emotions of racism. }\end{array}$ & $10.5(10)$ & $32.6(31)$ & $26.3(25)$ & $26.3(25)$ & $4.2(4)$ \\
\hline
\end{tabular}

Note. This table presents information about the survey questions that were asked to gain information about participants' experience and perceptions related to emotions and race. $\mathrm{POC}=$ people of color.

participants reported that they were comfortable talking about race and racism with colleagues $(n=107,70.4 \%)$, with only a small number indicating that they would be uncomfortable ( $n$ $=18,11.8 \%)$. This is consistent with results indicating that they would be comfortable versus uncomfortable talking with others in general.

In regard to the role of $\mathrm{ABA}$ in reducing racism and systematic oppression, almost all participants $(n=139,91.4 \%)$ agreed that the field of ABA should be involved in reducing racism and systematic oppression; however, a smaller number ( $n=124,81.6 \%$ ) agreed that behavior analysts should create interventions to address the emotions related to racism and oppression. Whereas only $3.9 \%(n=6)$ disagreed with this statement, $14.5 \%(n=22)$ indicated that they did not know. When responses were examined separately for POC compared to White individuals, a similar number of participants indicated that they agreed that the field of ABA should be involved in reducing racism and systematic oppression $(n=$ $49,92.5 \%)$ and $91.5 \%(n=87)$ respectively). However, a small number of POC were not in agreement $(n=3,5.7 \%)$ with this statement (Fig. 3).

Overall, most participants indicated that both helping clients feel better emotionally and understanding emotions related to racism are important. More than $80 \%$ indicated that behavior analysts should create interventions that address the emotions associated with racism and oppression. However, over half of the participants indicated that the field of behavior analysis does not respond to emotion nor consider emotion in the analysis of and intervention on behavior (see Fig. 1). These data suggest a disconnect between what is important about emotions to these practitioners and how well they think the field addresses these issues.
Fig. 1 Emotions of Racism Within Applied Behavior Analysis. Note. This figure presents aggregated data for survey questions related to the importance of emotions within the field of applied behavior analysis, the importance of developing interventions aimed at addressing emotions of racism, and the response of the field to emotions within analysis and intervention of behavior

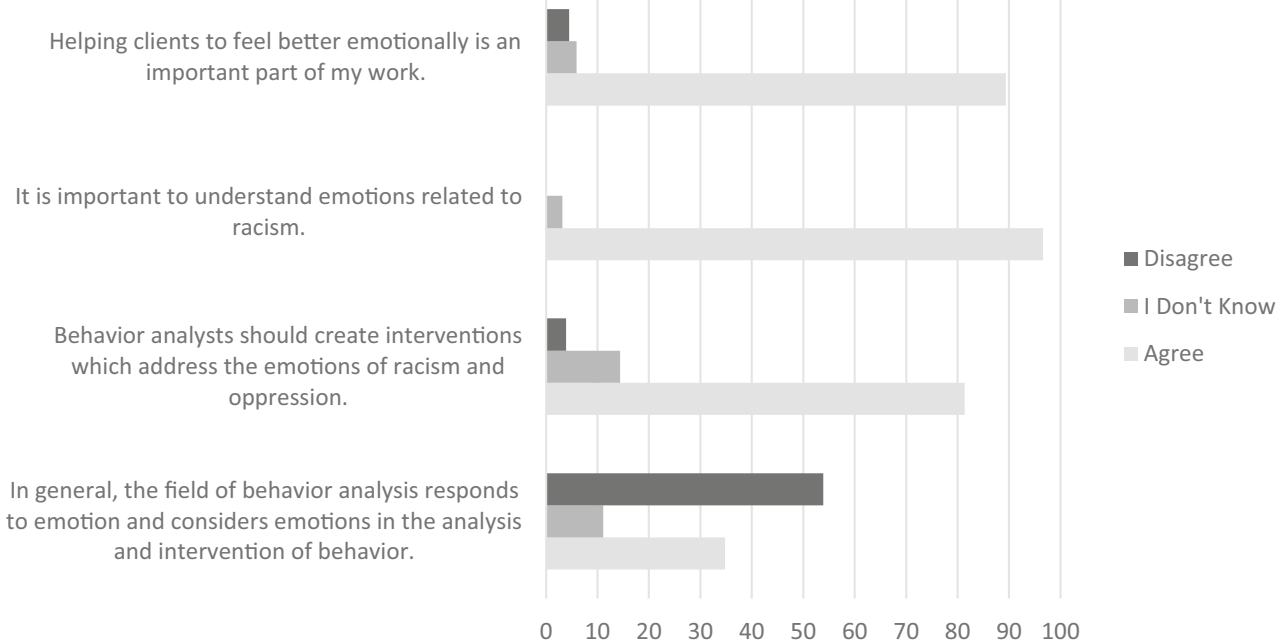


Fig. 2 Emotions of Racism Word Cloud. Note. This figure presents a word cloud of emotions participants identified as those likely to be experienced by people of color who experience systemic racism. The larger the word, the more often it was mentioned by participants

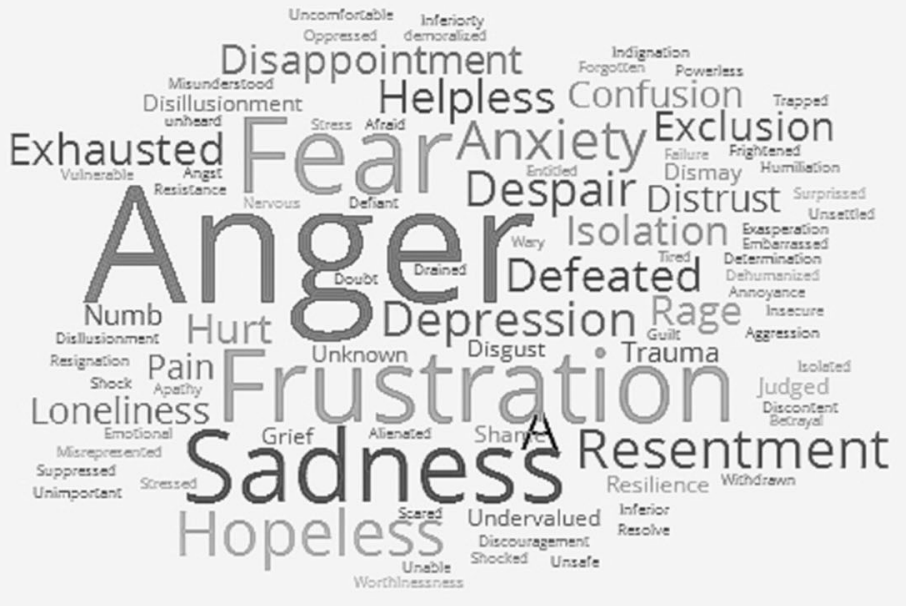
Disillusionment Helpless Confusion traps: xhausted Resistanse Nenous $=$ Defiant Despair Distrust surpisses $\triangle O N$ Woy Isolation Evaspersas 1 Doub deated Defeated Numb Hurt $\longrightarrow$ Depression Rage masus Unknown Disgust o Trauma oneliness Sâd

\section{Discussion and Recommendations}

How can behavior scientists and practitioners help end a pandemic of racism? Racism is both an individual and a systemic problem, perpetuated by behavior and emotion. To make a difference, we need to start by identifying and defining both, so we can gain a greater understanding of what each may entail. Such a task may require us to reflect on our experiences and then engage in difficult discussions. We may need to notice and share our emotions, or we may need to listen with empathy and curiosity and ask the right questions to learn about the perspectives of others (Spitzberg \& Changnon, 2009). Then, as a field, we can begin to employ our scientific principles and processes to analyze the contingencies maintaining the behaviors and emotions of racism and begin to change them. We can change the pain of racism only by changing the contingencies of which it is a part (see T. V. J. Layng et al., in press).

\section{How Can Sharing Our Emotions Help Us Dismantle Racism?}

Emotional prejudices felt toward racial minority outgroups are more closely related to discrimination than are beliefs and stereotypes thought about them. ... Given these findings, the analysis of intergroup emotions offers possibilities for further understanding discrimination. (Talaska et al., 2008, p. 263)

The survey results confirm that many professionals working in the field of ABA take emotions into consideration as they work with their clients. Most participants reported that client and caregiver emotions are important in the assessment process, and those client emotions may impact intervention development or revision. The majority agreed that an

Table 4 Applied Behavior Analysis (ABA) and Racism

\begin{tabular}{|c|c|c|c|c|c|}
\hline \multirow[t]{2}{*}{ Survey item } & \multicolumn{5}{|l|}{ Level of comfort } \\
\hline & $\begin{array}{l}\text { Very } \\
\text { comfortable } \\
\quad \%(n)\end{array}$ & $\begin{array}{c}\text { Comfortable } \\
\%(n)\end{array}$ & $\begin{array}{l}\text { Neutral \% } \\
\quad(n)\end{array}$ & $\begin{array}{l}\text { Uncomfortable } \\
\quad \%(n)\end{array}$ & $\begin{array}{l}\text { Very } \\
\text { uncomfortable } \\
\%(n)\end{array}$ \\
\hline \multirow{2}{*}{$\begin{array}{l}\text { How comfortable are you discussing race with your } \\
\text { behavior-analytic colleagues? }\end{array}$} & $24.3(37)$ & $46.0(70)$ & $17.7(27)$ & $10.5(16)$ & $1.3(2)$ \\
\hline & \multicolumn{5}{|c|}{ Level of agreement } \\
\hline Survey item & $\begin{array}{l}\text { Strongly agree } \\
\%(n)\end{array}$ & Agree $\%(n)$ & $\begin{array}{l}\text { I don't know } \\
\%(n)\end{array}$ & Disagree $\%(n)$ & $\begin{array}{l}\text { Strongly disagree } \\
\%(n)\end{array}$ \\
\hline $\begin{array}{l}\text { The field of ABA should be involved in reducing racism and } \\
\text { systematic oppression. }\end{array}$ & $67.1(102)$ & $24.3(37)$ & $5.9(9)$ & $1.3(2)$ & $1.3(2)$ \\
\hline $\begin{array}{l}\text { Behavior analysts should create interventions that address the } \\
\text { emotions of racism and oppression. }\end{array}$ & $45.3(69)$ & $36.1(55)$ & $14.4(22)$ & $3.9(6)$ & $0(0)$ \\
\hline
\end{tabular}

Note. This table presents information about the survey questions that were asked to gain information about participants' experience and perceptions related to $\mathrm{ABA}$ and racism. 
important part of our work is to help people feel better emotionally. Yet, although most of us are comfortable discussing emotions and displaying empathy, a number of us do feel somewhat uncomfortable displaying our own emotions or witnessing the emotional behavior of others. This finding is unsurprising, as many individuals experience discomfort related to the display and observation of emotion (Bebane et al., 2015). Further, there are "historical relations of power that prompt emotional resistance to discussions of race" (Srivastava, 2006, p. 50). Such discomfort is a barrier, though, when we need to talk about the trauma of racism. We may not yet understand how to intervene in the contingencies maintaining racism, but discussing our emotions could be an important first step (American Psychological Association, n.d.). Indeed, emotions are an integral aspect of the patterns and contingencies that maintain systemic racism (Feagin, 2010; Spanierman \& Cabrera, 2015).

The consistent negative emotional states associated with racism indicate, urgently, that we must make changes in contingencies - even if we cannot yet describe all of the reinforcers, consequences, or learning histories related to our experience (see Layng et al., in press). In other words, we know that we must act to make changes in our environments because we do know we are experiencing negative emotions due to the current contingencies acting within these environments. This is true even if we cannot fully explain the complexity of "why." The Black experience of racism often includes depression, anger, confusion, tension, fatigue, and other negative feelings (Carter \& Reynolds, 2011). This is something that we know; these emotions were identified in the current survey and align with the wider literature. Although we may not know the specifics of the contingencies surrounding these emotions, we can recognize that they are "sensible outcomes of each individual's personal interaction with the environment, in particular the consequential contingencies that shaped and maintain the pattern" (T. V. J. Layng et al., in press, pp. 6-7).

A recommendation to share emotions of racism raises two important questions. First, why should members of the Black community share their emotions? Of course, no one should ever be pressured to share their emotional account of racism or to tell the White community about how they feel; it is not the responsibility of Black individuals to educate others on their experience or their feelings (DiAngelo, 2018), and requests for them to do so can create a heavy burden (Burgin, 2018). Choosing to share is a personal choice based on what is best for each individual. In addition, it must be recognized that there are long-standing barriers to talking about emotions within the power structures of racism. Black individuals are acutely aware of the stereotypes that often accompany their expression of emotion, particularly their expression of negative emotions such as anger and frustration, and the contingencies that are in place when they do so (González-Prendes \& Thomas, 2011; Magee \& Louie, 2016). As a result, Black individuals may be more inclined to hold back, as they may see no point in talking about their feelings (Adair \& Howell, 1988; Oluo, 2019); this in itself may lead to an increase in their likelihood of experiencing negative emotions (Adair \& Howell, 1988). For those experiencing racism, though, there may be mental health benefits to voicing the pain and the trauma and to acknowledging their experiences and the experiences of their community (American Psychological Association, n.d.; Torre \& Lieberman, 2018). These assertions can then be harnessed by members of the Black community and society at large to fuel actions for change (see American Psychological Association, n.d.; T. V. J. Layng et al., in press).

The other question is, why should we discuss the White experience of racism? Within the power structures of racism, truly reciprocal conversations can be difficult (Adair \& Howell, 1988): "Too often whites at discussions on race decide for themselves what will be discussed, what they will hear, what they will learn" (Oluo, 2019, introduction). They may not listen, they may dismiss or interrupt, and they may raise their voices, discounting the contributions of others (Adair \& Howell, 1988; Oluo, 2019). These behaviors make real dialogue difficult. Yet, if systemic racism is maintained
Fig. 3 Should the Field of Applied Behavior Analysis Be Involved in Reducing Racism and Systematic Oppression? Note. This figure presents aggregated data for participant responses to the survey question, separated for both people of color (POC) and White individuals
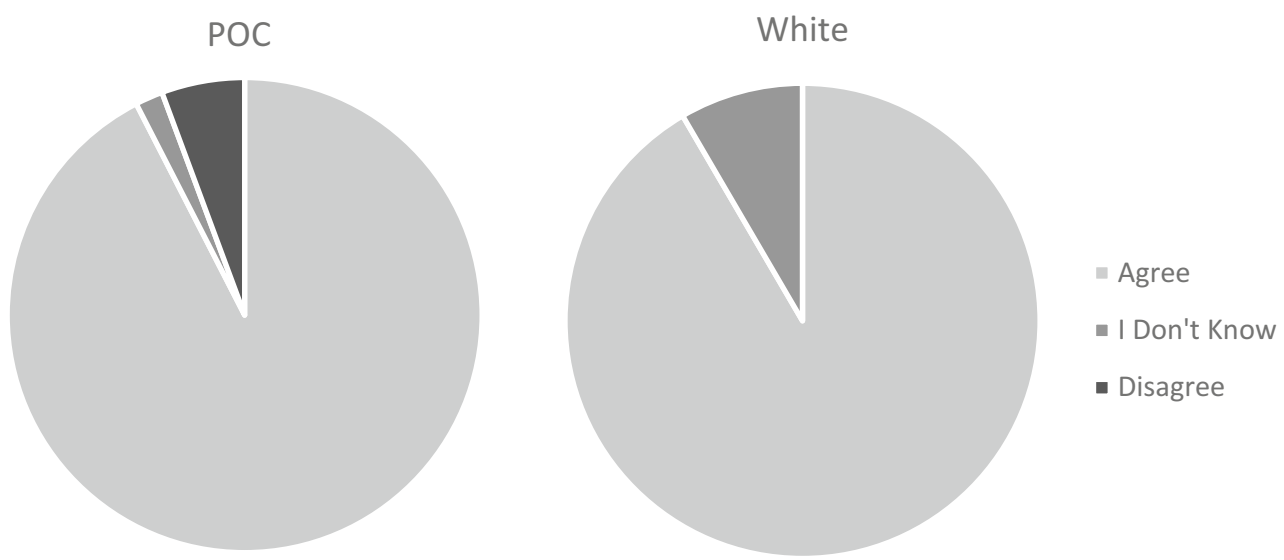
by a combination of how White people think and feel about issues of race (Feagin, 2010), in addition to how they behave, then the behaviors and emotions of White racism (e.g., apathy, fear, sadness, rage, shame, empathy) and antiracism (e.g., empathy, outrage, productive guilt, compassion, relief, hope) may be informative (Spanierman \& Cabrera, 2015). Interestingly, a behavior analysis of the emotions of racism suggests that prejudice, as demonstrated by behaviors such as "White flight," may be founded in fear and, thus, actions aimed at distancing oneself from a particular group. Similarly, bigotry may be founded in anger and may result in efforts that push others away (R. R. Layng \& Robbins, 2012). However, few studies in any field have examined these issues (Cabrera, 2014).

\section{Can White People Better Understand the Emotional Experiences of Racism?}

Most White people go cradle to grave in racial segregation. Most White people do not have authentic sustained relationships across race, particularly with black people.

—Robin DiAngelo (LaMotte, 2020, q. 2, para. 2)

Most of the survey respondents strongly felt that it is important to understand the emotional aspects of racism, even though many also indicated that they did not feel completely comfortable talking about issues of race with others. Importantly, there was some disagreement about whether or not a White person can actually understand the emotional experiences of racism. As calls are made for behavior scientists and practitioners to become more actively involved in the work needed to address racism, this is an important question that we need to explore in greater detail. Behavior analysis is a predominantly White field (Capell, 2019; Connors, 2020), with about $56 \%$ of certificants surveyed by the BACB identifying as White; among BCBAs and BCBA-Ds, the percentage was higher, at almost $72 \%$. Conversely, only $7.99 \%$ of certificants identified as Black; among BCBAs and BCBADs, the percentage was just 3.6 (BACB, 2020). ${ }^{1}$ As such, understanding more about a White person's ability to truly understand racism is important, as is the understanding that it may involve, or is likely to involve, an active journey of personal development (Spanierman \& Cabrera, 2015) along a continuum from active racism, to unintentional racism, to nonracist behavior, and ultimately antiracist (Sue, 2017) and pro-social justice behavior.

\footnotetext{
${ }^{1}$ However, it should be noted that the BACB survey did not provide a way to identify with multiple races/ethnicities. The results may have differed if the survey permitted respondents to select more than one.
}

White individuals may better understand the experience of racism through the development of empathy and compassion. Empathy, which is different from sympathy or pity, is closely related to the affective experience of emotion. However, empathy includes more than just "feeling what others feel." It also requires active perspective taking and a desire to alleviate suffering (Catagnus \& Rock, 2020). When we move from empathy to action, we are demonstrating compassion (Taylor et al., 2019). From one behavioral point of view, "empathy is contacting the context and consequences that others may face and having that influence how one behaves toward others" (T. V. J. Layng, 2016, p. 27). It involves recognizing, sharing, and understanding the feelings of others (McMahon \& Rosenthal, 2018). Another theory posits that deictic framing, one of the relational operants described in relational frame theory, is related to empathy and to how we make meaning of what others tell us about their experiences (Vilardaga, 2009).

Though researchers in behavior analysis may study empathy from different theoretical viewpoints, one thing seems clear: We can all learn new behaviors to better demonstrate empathy and compassion (Taylor et al., 2019). Similarly, we can improve our ability to understand the worldviews of others. Perspective taking, or imagining the thoughts and feelings of someone else, is one aspect of empathy, and it often happens without conscious effort. Yet we also often need to actively try to understand the perspectives of others. We must deeply value others' viewpoints and experiences if we hope to overcome our biases, learning history, and immediate experience (Tamir \& Mitchel, 2011) - which is extremely hard. It is quite challenging to imagine or fully comprehend how others' experiences, thoughts, and feelings can be so very different from our own.

At the simplest level, talking openly about these differences can help us understand each other and share those perspectives (Catagnus \& Rock, 2020). Of course, it is hard to do this if we still feel uncomfortable talking about emotions or sharing the emotional experience of someone else. Dialogue about racism, for example, often requires deep, and even uncomfortable, personal development (DiAngelo, 2018). Reflecting on our own values while also considering the values and cultures of others is important (Fong et al., 2016), but not easy. However, there are types of questions we can ask to understand how others' experiences relate to their perspectives (Barnes-Holmes et al., 2001; Davlin et al., 2011; McHugh et al., 2004). Understanding the contingencies operating on someone's behavior facilitates empathy and compassion toward them as well (Heagle \& Rehfeldt, 2006). Thus, empathy, compassion, and perspective taking are closely related processes and behaviors that, together, could help us understand the experience of racism. Interestingly, these are also skills and processes necessary for acting as a White ally (DeTurk, 2011) to the Black community, along with self-reflection, learning about racism and 
privilege, valuing equity, and collaborating with $\mathrm{POC}$ in our actions to overcome racism (Spanierman \& Smith, 2017, as summarized by Sue, 2017).

\section{Can the Science of Behavior Analysis Help End a Pandemic of Racism?}

It's up to all of us - Black, white, everyone - no matter how well-meaning we think we might be, to do the honest, uncomfortable work of rooting it out. It starts with self-examination and listening to those whose lives are different from our own. It ends with justice, compassion, and empathy that manifests in our lives and on our streets.

—Michelle Obama (Obama, 2020)

One troubling finding of this survey is that, generally, behaviorists do not feel confident that the science of behavior analysis is doing enough to respond to or to consider emotions, which are clearly part of the experience of racism. This makes sense, as the field certainly has not done much to address racism overall (Matsuda et al., 2020). It seems obvious that behavior analysis needs more research, applied solutions, dissemination efforts, and professional training to intervene against racism. As discussed previously, one first step to identifying and understanding the behaviors and emotions of racism, to better understand the contingencies of which these behaviors and emotions are a part (R. R. Layng \& Robbins, 2012; T. V. J. Layng et al., in press), is to facilitate discussion between those who have experienced racism and those who have systemically benefited from it. There are risks to engaging in racial dialogue, though, especially if done haphazardly. Dialogue must go beyond talk and must identify steps that can lead to social action. Talking can lead to adverse outcomes if it includes tone policing or the silencing of expressions of pain, or if it is conducted in a way that upholds existing power structures: "If not designed well, dialogues can perpetuate misunderstandings, result in silence, create tension, and bring about feelings of anxiety, anger, and awkwardness" (Ramasubramanian \& Wolfe, 2020, para. 5). Because traditional training in behavior analysis does not necessarily require specialized training in dialogue or in ways to facilitate difficult conversations (see the BACB Task List; BCBA, 2017), we may need to learn the skill of interracial dialogue in our professional community. Perhaps we all need more focused training, mentorship, and practice to skillfully develop understandings with each other, with our clients, and with the wider community. There are numerous suggestions and ideas to be drawn from other fields in regard to higher education (Werman et al., 2019), preprofessional training (e.g., Daniel, 2009), and comfort with dialogue about race in clinical interactions (e.g., Cardemil \& Battle, 2003) or in the workplace (Hatmaker, 2016). The field of behavior analysis would likely benefit from more research, training, and focus on how to talk about race, especially during this painful and urgent time.

Despite a relative paucity of research, as it relates to all facets of racism-related behavior and emotion, varied behavioral strategies for dismantling racism at different levels of intervention have been proposed, discussed, or tested empirically. Drawn from contextual/functional (Guerin, 2005) and behavior analyses, examples include perspective-taking protocols, mindfulness-based interventions, bias-reduction research, context or contingency changes, and valuesclarification exercises (for a more detailed review, see Matsuda et al., 2020). In recent years, researchers have suggested that acceptance and commitment training (ACTr), which includes interventions related to private behaviors (including emotions), might help reduce racial bias (Levin et al., 2016; Lillis \& Hayes, 2007) and prejudice (Krafft et al., 2018). The ACTr approach incorporates aspects of mindfulness, acceptance, and values clarification to help individuals behave in ways that align with their values (S. C. Hayes et al., 2013), even when some aspect of doing so includes painful emotions (Gould et al., 2018).

Thus, behavior science could be instrumental in correcting the contingencies that are maintaining systemic racism. However, this is unlikely to occur unless more of us choose to become involved in this effort. As mentioned previously, the emotions of racism are not incidental. They are key to understanding the contingencies maintaining systemic racism and oppression. As a result, it is imperative that we, as a field, engage in necessary activities to attempt to reach a consensus on the role of emotion in the analysis of behavior and then begin the important work to advance our research and, ultimately, intervention in this area. Although the discussion of emotion is not new within the field of behavior analysis, the current social justice movement and the recognition of racism as a public health crisis put this discussion into a new and urgent context.

Author Note All authors share first-author status. We appreciate the helpful guidance and support of T. V. Joe Layng.

Data Availability The results of the current study are available from the corresponding author on reasonable request.

\section{Declarations}

DeclarationsCode availability Not applicable.

Ethical approval The questionnaire and methodology for this study were approved by the Institutional Review Board of the Chicago School of Professional Psychology (Approval IRB-20-07-0027). 
Consent to participate Informed consent was obtained from all individual participants included in the study.

Consent for publication Participants signed informed consent regarding publishing their data.

Conflicts of interest/competing interests The authors declare that they have no conflict of interest.

\section{References}

Adair, M., \& Howell, S. (1988). The subjective side of politics, breaking old patterns, weaving new ties: Alliance building, and democracy at work. Tools for Change.

American Psychological Association. (n.d.). We must unmute. https:// www.apa.org/news/events/my-brothers-keeper

American Psychological Association. (2020). "We are living in a racism pandemic” says APA president. https://www.apa.org/news/press/ releases/2020/05/racism-pandemic

Anderson, C. M., Hawkins, R. P., Freeman, K. A., \& Scotti, J. R. (2000). Practice events: Do they belong in a science of human behavior? The Behavior Analyst, 23(1), 1-10. https://doi.org/10.1007/ BF03391995.

Baker, C. (2020). In a pandemic, all some people see is your color. The Atlantic. https://www.theatlantic.com/magazine/archive/2020/06/ coronavirus-racism/610609/

Barnes-Holmes, Y., Barnes-Holmes, D., Roche, B., \& Smeets, P. M. (2001). Exemplar training and a derived transformation of function in accordance with symmetry. The Psychological Record, 51, 287308. https://doi.org/10.1007/BF03395400.

Baum, W. M. (2011). Behaviorism, private events, and the molar view of behavior. The Behavior Analyst, 34(2), 185-200. https://doi.org/10. 1007/BF03392249.

Bebane, S., Flowe, H. D., \& Maltby, J. (2015). Re-refining the measurment of distress intolerance. Personality and Indiviual Differences, 85, 159-164. https://doi.org/10.1016/j.paid.2015.05. 005

Behavior Analyst Certification Board. (2017). BCBA/BCaBA task list (5th ed.).

Behavior Analyst Certification Board. (2020). BACB certificant data. Retrieved March 12, 2021, from https://www.bacb.com/bacbcertificant-data

Biernacki, P., \& Waldorf, D. (1981). Snowball sampling: Problems and techniques of chain referral sampling. Sociological Methods \& Research, 10(2), 141-163. https://doi.org/10.1177/ 004912418101000205 .

Burghardt, G. M. (2019). A place for emotions in behavior systems research. Behavioural Processes, 166, 103881. https://doi.org/10. 1016/j.beproc.2019.06.004.

Burgin, S. (2018). Black Lives Matter, Black power, and the role of White allies. Black Perspectives. https://www.aaihs.org/black-livesmatter-black-power-and-the-role-of-white-allies/

Cabrera, N. L. (2014). "But I'm oppressed too": White male college students framing racial emotions as facts and recreating racism. International Journal of Qualitative Studies in Education, 27(6), 768-784. https://doi.org/10.1080/09518398.2014.901574.

Capell, S. T. (2019). The current status of African Americans within the field of applied behavior analysis. Covenant, 15, $16 \mathrm{https} / / / \mathrm{www}$. covenant1516.org/blogs/2019/6/6/the-current-status-of-africanamericans-within-the-field-of-applied-behavior-analysis.

Cardemil, E. V., \& Battle, C. L. (2003). Guess who's coming to therapy? Getting comfortable with conversations about race and ethnicity in psychotherapy. Professional Psychology: Research and
Practice, 34(3), 278-286. https://doi.org/10.1037/0735-7028.34. 3.278.

Carter, R. T., \& Reynolds, A. L. (2011). Race-related stress, racial identity status attitudes, and emotional reactions of Black Americans. Cultural Diversity and Ethnic Minority Psychology, 17(2), 156162. https://doi.org/10.1037/a0023358.

Catagnus, R. M., \& Rock, D. R. (2020). Perspective taking: The neuroscience of better workplace relationships. NeuroLeadership Journal, 9(2).

Catania, A. C. (2011). On Baum's public claim that he has no significant private events. The Behavior Analyst, 34(2), 227-236. https://doi. org/10.1007/BF03392254.

Connors, B. (2020). Where is the diversity in applied behavior analysis? Brian Connors, Ph.D., BCBA: Blog on All Things Behavior Analysis https://www.brianconnersbcba.com/blog/where-is-thediversity-in-applied-behavior-analysis.

Daniel, B. J. (2009). Conversations on race in teacher education cohorts. Teaching Education, 20(2), 175-188. https://doi.org/10.1080/ 10476210902730497.

Davlin, N. L., Rehfeldt, R. A., \& Lovett, S. (2011). A relational frame theory approach to understanding perspective-taking using children's stories in typically developing children. European Journal of Behavior Analysis, 12, 403-430. https://doi.org/10.1080/ 15021149.2011.11434392.

DeTurk, S. (2011). Allies in action: The communicative experiences of people who challenge social injustice on behalf of others. Communication Quarterly, 59(5), 569-590. https://doi.org/10. 1080/01463373.2011.614209.

DiAngelo, R. J. (2018). White fragility: Why it's so hard for White people to talk about racism. Beacon Press.

Dymond, S., Bennett, M., Boyle, S., Roche, B., \& Schlund, M. (2018). Related to anxiety: Arbitrarily applicable relational responding and experimental psychopathology research on fear and avoidance. Perspectives on Behavior Science, 4l(1), 189-213. https://doi.org/ 10.1007/s40614-017-0133-6.

Feagin, J. R. (2010). The White racial frame: Centuries of racial framing and counter-framing. Routledge.

Fong, E. H., Catagnus, R. M., Brodhead, M. T., Quigley, S., \& Field, S. (2016). Developing the cultural awareness skills of behavior analysts. Behavior Analysis in Practice, 9(1), 84-94. https://doi.org/10. 1007/s40617-016-0111-6.

Friman, P. C., Hayes, S. C., \& Wilson, K. G. (1998). Why behavior analysts should study emotion: The example of anxiety. Journal of Applied Behavior Analysis, 31(1), 137-156. https://doi.org/10.1901/ jaba.1998.31-137.

Fryling, M. J., \& Hayes, L. J. (2015). Similarities and differences among alternatives to Skinner's analysis of private events. The Psychological Record, 65(3), 579-587. https://doi.org/10.1007/ s40732-015-0130-7.

Goldiamond, I. (1979). Emotions and emotional behavior: A consequential analysis and treatment. BMA Audio Cassettes.

González-Prendes, A. A., \& Thomas, S. A. (2011). Powerlessness and anger in African American women: The intersection of race and gender. International Journal of Humanities and Social Science, 1(7), 1-8. https://doi.org/10.1080/07399330802523709.

Gould, E. R., Tarbox, J., \& Coyne, L. (2018). Evaluating the effects of acceptance and commitment training on the overt behavior of parents of children with autism. Journal of Contextual Behavioral Science, 7, 81-88.

Guerin, B. (2005). Combating everyday racial discrimination without assuming racists or racism: New intervention ideas from a contextual analysis. Behavior and Social Issues, 14(1), 46-71. https://doi. org/10.5210/bsi.v14i1.120.

Hatmaker, D. M. (2016). Breaking the silence: How conversations about race can influence work practices and interactions. Journal of Public 
Administration Research and Theory, 26(2), 395-398. https://oi. org/10.1093/jopart/muv031.

Hayes, L. J., \& Fryling, M. J. (2015). A historical perspective on the future of behavior science. The Behavior Analyst, 38(2), 149-161. https://doi.org/10.5514/rmac.v37.i1.24686.

Hayes, S. C., Levin, M. E., Plumb-Vilardaga, J., Villatte, J. L., \& Pistorello, J. (2013). Acceptance and commitment therapy and contextual behavioral science: Examining the progress of a distinctive model of behavioral and cognitive therapy. Behavior Therapy, 44(2), 180-198.

Heagle, A. I., \& Rehfeldt, R. A. (2006). Teaching perspective-taking skills to typically developing children through derived relational responding. Journal of Early and Intensive Behavior Intervention, 3(1), 1-34. https://doi.org/10.1037/h0100321.

Khaw, M. (2020). Students and staff express "rage" and "sadness" following the killing of George Floyd, encouraging others to act against racism. The La Salle Falconer. https://lasallefalconer.com/ 2020/06/students-and-staff-express-rage-and-sadness-followingthe-killing-of-george-floyd-encourage-others-to-act-againstracism/

Krafft, J., Ferrell, J., Levin, M. E., \& Twohig, M. P. (2018). Psychological inflexibility and stigma: A meta-analytic review. Journal of Contextual Behavioral Science, 7, 15-28.

LaMotte, S. (2020). Robin DiAngelo: How "White fragility" supports racism and how Whites can stop it. CNN. https://www.cnn.com/ 2020/06/07/health/white-fragility-robin-diangelo-wellness/index. html

Layng, R. R., \& Robbins, J. K. (2012). Toward a new consequentialism: Nonlinear contingency analysis and the understanding of moral behavior [Poster presentation]. In Theory and Philosophy Conference, Association for Behavior Analysis International, November 3, 2012. United States.

Layng, T. V. J. (2006). Emotions and emotional behavior: A constructional approach to understanding some social benefits of aggression. Brazilian Journal of Behavior Analysis, 2(2), 155-170.

Layng, T. V. J. (2016). Converging qualities of personal competencies. In M. Murphy, S. Redding, \& J. Twyman (Eds.), Handbook on personalized learning for states, districts, and schools (pp. 19-36). Temple University; Center for Innovations in Learning.

Layng, T. V. J. (2017). Private emotions as contingency descriptors: Emotions, emotional behavior, and their evolution. European Journal of Behavior Analysis, 18, 168-179. https://doi.org/10. 1080/15021149.2017.1304875.

Layng, T. V. J., Andronis, P. T., Codd, R. T., \& Abdel-Jalil, A. (in press). Nonlinear contingency analysis: Going beyond cognition and behavior in clinical practice. Routledge.

Levin, M. E., Luoma, J. B., Vilardaga, R., Lillis, J., Nobles, R., \& Hayes, S. C. (2016). Examining the role of psychological inflexibility, perspective taking, and empathic concern in generalized prejudice. Journal of Applied Social Psychology, 46, 180-191.

Lewon, M., \& Hayes, L. J. (2014). Toward an analysis of emotions as products of motivating operations. The Psychological Record, 64(4), 813-825. https://doi.org/10.1007/s40732-014-0046-7.

Lillis, J., \& Hayes, S. C. (2007). Applying acceptance, mindfulness, and values to the reduction of prejudice: A pilot study. Behavior Modification, 31, 389-411.

Magee, W., \& Louie, P. (2016). Did the difference between Black and White Americans in anger-out decrease during the first decade of the twenty-first century? Race and Social Problems, 8(3), 256-270. https://doi.org/10.1007/s12552-016-9178-5.

Matsuda, K., Garcia, Y., Catagnus, R., \& Ackerlund Brandt, J. A. (2020). Can behavior analysis help us understand and reduce racism? A review of the current literature. Behavior Analysis in Practice, 13, 336-347. https://doi.org/10.1007/s40617-02000411-4.
McHugh, L., Barnes-Holmes, D., \& Barnes-Holmes, Y. (2004). A relational frame account of the development of complex cognitive phenomena: Perspective-taking, false belief understanding, and deception. International Journal of Psychology and Psychological Therapy, 4, 303-324.

McMahon, K. B., \& Rosenthal, Z. M. (2018). Situated empathy: Applying contextualism to the science of recognizing other people's emotions. In D. S. Wilson \& S. C. Hayes (Eds.), Evolution and contextual behavioral science: An integrated framework for understanding, predicting, and influencing human behavior (pp. 133148). New Harbinger Publications.

Nosik, M. R., \& Grow, L. L. (2015). Prominent women in behavior analysis: An introduction. The Behavior Analyst, 38(2), 225-227. https://doi.org/10.1007/s40614-015-0032-7.

Obama, M. [@MichelleObama]. (2020).It's up to all of us-Black,white, everyone-no matter how well-meaning we think we might be [Tweet]. Twitter. https://twitter.com/michelleobama/status/ 1291740999748857858

Oluo, I. (2019). Confronting racism is not about the needs and feelings of White people. The Guardian. https://www.theguardian.com/ commentisfree $/ 2019 / \mathrm{mar} / 28 /$ confronting-racism-is-not-about-theneeds-and-feelings-of-white-people

Palmer, D. C., Eshleman, J., Brandon, P., Layng, T. V. J., McDonough, C., Michael, J., Schoneberger, T., Stemmer, N., Weitzman, R., \& Normand, M. (2004). Dialogue on private events. The Analysis of Verbal Behavior, 20(1), 111-128. https://doi.org/10.1007/ BF03392998.

Ramasubramanian, S., \& Wolfe, A. (2020). The promise and perils of interracial dialogue. National Communication Association. https:// www.natcom.org/communication-currents/promise-and-perilsinterracial-dialogue

Spanierman, L. B., \& Cabrera, N. L. (2015). The emotions of White racism and antiracism. Unveiling Whiteness in the 21st century: Global manifestations, transdisciplinary interventions, 9-28. Lexington Books.

Spanierman, L. B., \& Smith, L. (2017). Roles and responsibilities of White allies: Implications for research, teaching, and practice. The Counseling Psychologist, 45(5), 606-617. https://doi.org/10.1177/ 0011000017717712.

Spitzberg, B. H., \& Changnon, G. (2009). Conceptualizing intercultural competence. In D. K. Deardorff (Ed.), The SAGE handbook of intercultural competence ( $p p$. 2-52). Sage Publications.

Srivastava, S. (2006). Tears, fears and careers: Anti-racism and emotion in social movement organizations. Canadian Journal of Sociology, 31, 55-90. https://doi.org/10.1353/cjs.2006.0028.

Sue, D. W. (2017). The challenges of becoming a White ally. The Counseling Psychologist, 45(5), 706-716. https://doi.org/10.1177/ 0011000017719323.

Talaska, C. A., Fiske, S. T., \& Chaiken, S. (2008). Legitimating racial discrimination: Emotions, not beliefs, best predict discrimination in a meta-analysis. Social Justice Research, 21(3), 263-396. https:// doi.org/10.1007/s11211-008-0071-2.

Tamir, D. I., \&Mitchell, J. P. (2011). Social categorization and empathy for outgroup members. British Journal of Social Psychology, 48(3), 427-446.

Taylor, B. A., LeBlanc, L. A., \& Nosik, M. R. (2019). Compassionate care in behavior analytic treatment: Can outcomes be enhanced by attending to relationships with caregivers? Behavior Analysis in Practice, 12(3), 654-666. https://doi.org/10.1007/s40617-01800289-3.

Toney, D. E., \& Hayes, L. J. (2017). A behavioral analysis of apologies, forgiveness, and interpersonal conflict. Behavior and Social Issues, 26(1), 128-155. https://doi.org/10.5210/bsi.v26i0.7425.

Torre, J. B., \& Lieberman, M. D. (2018). Putting feelings into words: Affect labeling as implicit emotion regulation. Emotion Review, 10(2), 116-124. https://doi.org/10.1177/1754073917742706. 
Turnbull, M., Watson, B., Jin, Y., Lok, B., \& Sanderson, A. (2020). Vicarious trauma, social media and recovery in Hong Kong. Asian Journal of Psychiatry, 51, 102032. https://doi.org/10.1016/j.ajp. 2020.102032.

Vilardaga, R. (2009). A relational frame theory account of empathy. International Journal of Behavioral Consultation and Therapy, 5(2), 178-184. https://doi.org/10.1037/h0100879.
Werman, A., Adlparvar, F., Horowitz, J. K., \& Hasegawa, M. O. (2019). Difficult conversations in a school of social work: Exploring student and faculty perceptions. Journal of Social Work Education, 55(2), 251-264. https://doi.org/10.1080/10437797.2018.1520665.

Publisher's Note Springer Nature remains neutral with regard to jurisdictional claims in published maps and institutional affiliations. 